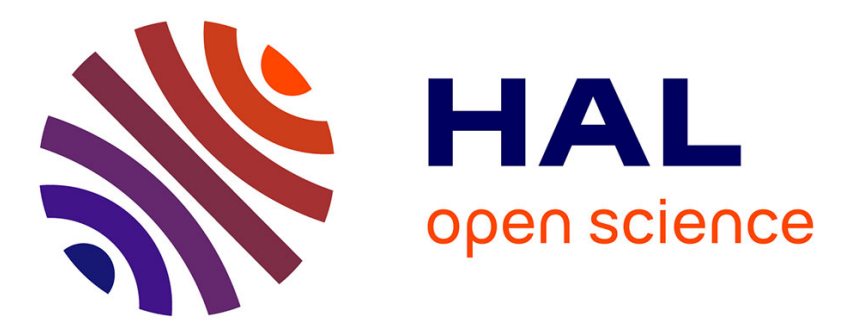

\title{
Three-dimensional Voronoi and multigrid model for microstructure contact problem
}

\author{
H. Boffy, P. Sainsot, Marie-Christine Baietto, T. Lubrecht
}

\section{To cite this version:}

H. Boffy, P. Sainsot, Marie-Christine Baietto, T. Lubrecht. Three-dimensional Voronoi and multigrid model for microstructure contact problem. ASME 2012 11Th Biennial Conference on Engineering Systems Design and Analysis, Jul 2012, Nantes, France. pp.587-589, 10.1115/ESDA2012-82526 . hal-01951690

\section{HAL Id: hal-01951690 \\ https://hal.science/hal-01951690}

Submitted on 13 Jun 2019

HAL is a multi-disciplinary open access archive for the deposit and dissemination of scientific research documents, whether they are published or not. The documents may come from teaching and research institutions in France or abroad, or from public or private research centers.
L'archive ouverte pluridisciplinaire HAL, est destinée au dépôt et à la diffusion de documents scientifiques de niveau recherche, publiés ou non, émanant des établissements d'enseignement et de recherche français ou étrangers, des laboratoires publics ou privés.

\section{(c)(1)}

Distributed under a Creative Commons Attribution| 4.0 International License 


\section{THREE-DIMENSIONAL VORONOI AND MULTIGRID MODEL FOR MICROSTRUCTURE CONTACT PROBLEM}

\author{
H. Boffy \\ Université de Lyon, CNRS \\ INSA-Lyon, LaMCoS UMR5259 \\ F-69621, France \\ Email: hugo.boffy@insa-lyon.fr
}

\author{
P. Sainsot* \\ M.C. Baietto and T. Lubrecht \\ Université de Lyon, CNRS \\ INSA-Lyon, LaMCoS UMR5259 \\ F-69621, France \\ Email: philippe.sainsot@insa-lyon.fr
}

\begin{abstract}
The prediction of both the tribological behaviour and mechanical analysis of the wear resistance are still of great research interest in order to improve the lifetime of material surfaces. This concerns both bulk and coated materials although coating processes have been often developed in order to protect substrates from tribological solicitations. The wear resistance of coated materials has been the subject of many studies which show that it is possible to protect and improve significantly the durability of substrates. A straightforward discretisation of the multi-scale problem of graded coatings on substrates exceed the memory and CPU capacity of current (and next generation) computers. The authors have proposed an efficient numerical model that can handle this multi-scale problem: using billion points and locally refined grids.
\end{abstract}

\section{NOMENCLATURE}

$\lambda_{x, y, z}, \mu_{x, y, z} \quad$ Lame coefficients

$\alpha_{x, y, z} \quad$ Dilatation coefficient

$E_{x, y, z} \quad$ Young's modulus of the material

$u_{i} \quad$ Displacements

a Radius of contact

$f$ friction coefficient

\footnotetext{
${ }^{*}$ Address all correspondence to this author.
}

\section{INTRODUCTION}

A three-dimensional model is proposed to analyse multiscale effects on material lifetime. Strains and stress fields are numerically computed within materials with graded coatings or containing inclusions or randomness heterogeneities. This model is based on multigrid techniques within a finite difference frame work. Localised refinement is implemented to optimize memory requirement and computing time. The Voronoi tessellation is used to generate the geometrical description of the grains. Each one possesses its own properties. After having presenting the 3D model and the numerical method used, some numerical results will be outlined before concluding on the possibilities of this new algorithm.

\section{D Model and numerical method Equation}

The work is based on a second order finite difference formulation of the 3D Lame equations. The Lame coefficients and the coefficient of thermal expansion can vary as a function of space. These equations can be generalised in terms of displacements $(\mathrm{u}(\mathrm{x}, \mathrm{y}, \mathrm{z}))$ to:

$$
\left(\lambda u_{j, j}\right)_{, i}+\left(\mu u_{i, j}\right)_{, j}+\left(\mu u_{j, i}\right)_{, j}-((3 \lambda+2 \mu) \alpha T)_{, i}=0
$$

The partial differential equations PDE are discretised using a second order finite difference scheme in the bulk except on the 
boundaries, where both Neumann (surface) and Dirichlet (other faces) boundary conditions are implemented.

\section{Multigrid methods}

The iterative methods converge slowly as the long wavelength errors present in the solution slowly diminishes with successive relaxation sweeps. MG techniques overcome this difficulty by using a sequence of coarsen grids. The grids communicate with one another through restriction and prolongation operators. Efficient multigrid algorithms for the solution of PDE require good ellipticity, which implies that non-smooth error components can be solved by local processing. The elasticity equations are elliptic and one can expect a good multigrid efficiency and convergence rate.

\section{Numerical results}

The domain studied is a half cube of finite dimensions. Hertzian loading is imposed on the upper surface and zero displacements are imposed on the other faces. The local refinement strategy [1] has been validated through a comparison with global calculations [2]. This strategy (100M of points in the restricted volume) allows one to deal with very fine layers or complex heterogeneities. Four different cases illustrate the model capabilities. The first one concerns a material with Young's modulus sinusoidal (wavelength $\bar{l}$ ) variation along depth (Fig. 1).
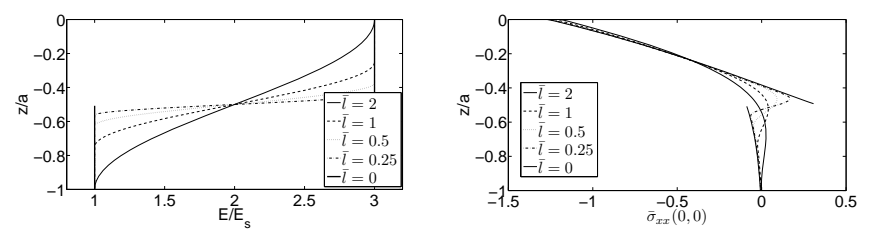

FIGURE 1. YOUNG MODULUS SINUSOIDAL VARIATION ALONG DEPTH AND TENSILE STRESS

The second one concerns a material containing a hard spherical inclusion located at the Hertzian depth submitted to a sliding Hertzian contact. Fig. 2 shows the Von-Mises stress $\left(\sigma_{V M}\right)$.

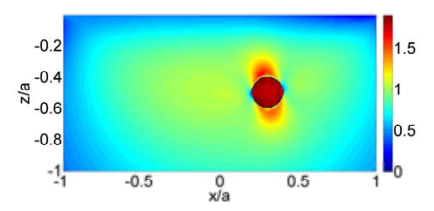

FIGURE 2. $\sigma_{V M}(\mathrm{X}, \mathrm{Y}=0, \mathrm{Z})$ FOR A HARD INCLUSION LOCATED AT X/A $=0.3, E_{I N C}=5 E, F=0.1$
This kind of problem can be generalized by considering a granular medium. The grains have different properties and are modelled using Voronoi Tessellation. Up to 2000 discretization points can be considered per grain. 32000 grains can be used to describe the potential interest zone located in the contact vicinity and corresponding to the finest grid. This simulation is performed with low CPU time and memory cost. Fig. 3 shows two examples. The former presents a plasma-spray deposition with linear variation of the deposit concentration (from $100 \%$ at the top surface to $0 \%$ at the interface), and the latter considers a $10 \%$ variation on the Young's modulus following a Gaussian distribution allocated to the grains. Fig. 4 illustrates $\sigma_{V M}$ in the midplane of the bulks under Hertzian loading.
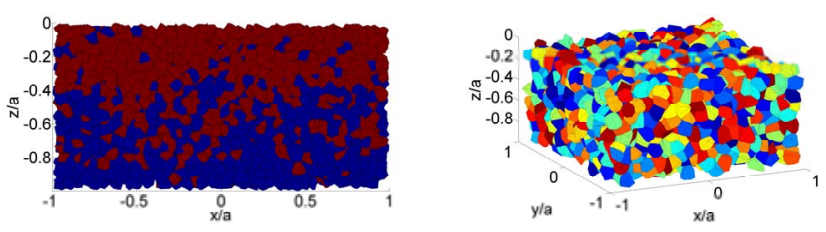

FIGURE 3. GRANULAR BULKS
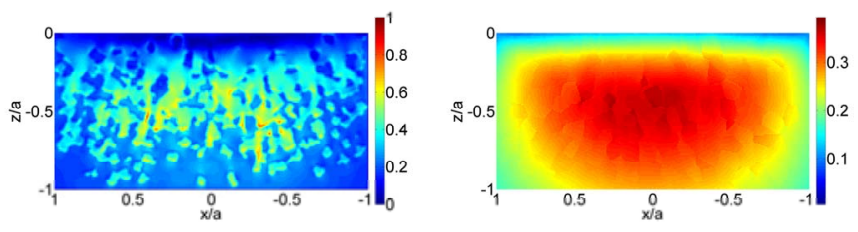

FIGURE 4. $\sigma_{V M}(\mathrm{X}, \mathrm{Y}=0, \mathrm{Z})$

\section{Discussion}

A discussion on the performed calculations is now presented showing the ability of the solver to deal with the different problems. A comparison of the CPU time versus the studied problem is given in Table 1. The heterogeneous materials are submitted to a classical Hertzian pressure $(a=1, P=1)$ at the top surface. Calculations have been performed using 8 levels with a local strategy (5 global levels, 3 refined levels) on a half cube of finite dimensions $L_{x}=L_{y}=2 * L_{z}=16 a$, leading to hundred million degrees of freedom (DoF) to solve.

It has been assumed that the convergence was reached for a $1.10^{-8}$ residual. Results show that the model is able to deal with all of these problems with low CPU time (less than one hour). The increase of the CPU time between the problems is due to the 


\begin{tabular}{|c|c|c|}
\hline Problem type & CPU time (min) & residual \\
\hline Homogeneous & 25 & $1.10^{-8}$ \\
\hline Inclusion: $E_{\text {inc }} / E=5$ & 27 & $1.10^{-8}$ \\
\hline Gaussian variation: $10 \%$ & 30 & $1.10^{-8}$ \\
\hline Linear variation: $E_{c} / E_{s}=3$ & 32 & $1.10^{-8}$ \\
\hline
\end{tabular}

TABLE 1. CPU TIMES FOR THE CONVERGED PROBLEMS

increase of the number of discontinuities in the materialwhich require more numerical relaxations to be solved.

\section{Conclusion}

A new 3D MG model able to deal with homogeneous and heterogeneous material is presented. This solver is able to use more than billion points to discretize the entire bulk on a personal computer. The next step will consist in the analysis of the material life based on different fatigue criteria and Weibull representations.

\section{REFERENCES}

[1] Bai, D., and Brandt, A., 1987. "Local mesh refinement multilevel techniques". J. Sci. Comput., 8, pp. 109-134.

[2] Boffy, H., Baietto, M. C., Sainsot, P., and Lubrecht, A. A., 2012. "An efficient $3 \mathrm{~d}$ model of functional graded materials for contact applications". Journal of Tribology. DOI: 10.1115/1.4006296. 